\title{
Endoscopic management of early colorectal cancer
}

\author{
Said Farhat ${ }^{1}$, Rawad yared ${ }^{2}$, Talal Elmais $^{3}$, Alex Malek $^{4}$, Imad El Hajij ${ }^{5}$ and Mansour Khoury ${ }^{6}$ \\ ${ }^{1}$ Department of Medicine, Division of Gastroenterology, Saint George Hospital University Medical Center, Achrafieh, Beirut, Lebanon \\ ${ }^{2}$ Department of Medicine, Division of Gastroenterology, Saint George Hospital University Medical Center, Achrafieh, Beirut, Lebanon \\ ${ }^{3}$ Department of Medicine, Division of Gastroenterology, Saint George Hospital University Medical Center, Achrafieh, Beirut, Lebanon \\ ${ }^{4}$ Department of Surgery, Division of General Surgery, Saint George Hospital University Medical Center, Achrafieh, Beirut, Lebanon \\ ${ }^{5}$ Department of Surgery, Division of General Surgery, Saint George Hospital University Medical Center, Achrafieh, Beirut, Lebanon \\ ${ }^{6}$ Department of Surgery, Division of General Surgery, Saint George Hospital University Medical Center, Achrafieh, Beirut, Lebanon
}

\begin{abstract}
The endoscopic treatment of cancerous and precancerous lesions in the gastrointestinal (GI) tract has experienced major breakthroughs in the past years. Colonoscopy plays a major role in the prevention and detection of colorectal cancer patients and is used for diagnosis and treatment of early colorectal cancer and its precursors. Improvements in colonoscopy preparation, new techniques of adenoma detection, and recent progress in endoscopic imaging methods are providing higher-quality results and thus reducing the incidence and mortality of the disease. During the past decade, endoscopic resection techniques have evolved, and cancers confined to the mucosal and superficial submucosal layers can now be resected via flexible endoscopes. Therefore, it is important to understand the indications and limitations of endoscopic resection, to determine whether the cancer can be curatively resected, and assess the risk of lymph node metastasis, which precludes endoscopic treatment.

The successful removal of an early colorectal cancer requires advanced techniques and expertise. Currently, many options are available such as snare polypectomy, that is the most frequently used, and endoscopic mucosal resection (EMR), that is an efficient method with low complication rate for the treatment of most benign and advanced lesions in the GI tract, but carries a risk of incomplete resection and recurrence of early cancer. However, with the introduction of precutting EMR or hybrid ESD, endoscopic submucosal dissection (ESD) and endoscopic full-thickness resection (EFTR), the scope of lesions eligible for curative endoscopic treatment has been widened significantly. These resection techniques have the potential to spare surgical treatment to a selected population of patients. We will review these different endoscopic techniques.
\end{abstract}

\section{Introduction}

The endoscopic removal of colorectal polyps reduces the incidence and mortality of colorectal cancer (CRC) and is considered an essential skill for endoscopists [1]. Endoscopic resection has experienced major breakthroughs in the last decades especially with the introduction of resection methods; the precutting EMR or hybrid ESD, endoscopic submucosal dissection (ESD) and endoscopic full-thickness resection (EFTR).Several quality criteria are required for curative endoscopic resection, such as 'en bloc' resection with free margins, combined with the quantification of the epithelial extent of invasion in malignant polypoid tumors i.e. Haggitt Classification.

This paper will review the different aspects of endoscopic treatment used in early colorectal cancer and highlight the progress that has been made. The advantages and disadvantages of each endoscopic therapy will be discussed.

\section{Early colorectal cancer}

Early colorectal cancer with a submucosal invasion depth of $\leq 1000$ $\mu \mathrm{m}$ and without lymphovascular/vascular invasion or tumor budding is traditionally considered as a low risk cancer with a risk of lymph node (LN) metastasis of $<1 \%[2,3]$. A systematic review and metaanalysis of histopathologic factors influencing the risk of LN metastasis in early colorectal cancer, by Beaton et al. [4] analysed 23 cohort studies including $>4000$ patients and reported that in early colorectal cancer a depth of submucosal invasion by the tumor of $>1 \mathrm{~mm}$, lymphovascular invasion, poor differentiation, and tumor budding are significantly associated with LN metastasis. However, the depth of submucosal invasion may often be subjective and not always reproducible between pathologists. Regarding tumor budding, an international consensus for the reporting, scoring, and assessment of tumor budding in colorectal cancer is accepted [5]. Tumor budding is an independent predictor of LN metastasis in pT1 colorectal cancer [6,7], and this scoring system should be part of the pathologic workup of early colorectal cancers. Yim et al. [8], evaluated a novel grading system associating tumor budding and the depth multiplied by the width measurements of submucosal invasion that can provide important information regarding lymph nodes metastasis in patients with submucosal invasive colorectal cancer. In addition to these traditional predictive markers of clinical outcome in colorectal cancer, the routine testing for molecular biomarkers, including mismatch repair (MMR) deficiency and microsatellite instability (MSI), is recommended because it offers additional molecular and biological information for the risk stratification of colorectal cancers [9]. Poor differentiation

${ }^{*}$ Correspondence to: Said Farhat, Department of Medicine, Division of Gastroenterology, Saint George Hospital University Medical Center, Achrafieh, Beirut, Lebanon, Tel: +961-1-441832, Fax: +961-1-449796, E-mail: saidfarhat@ hotmail.com

Key words: colon cancer, endoscopy, endoscopic mucosal resection, snare polypectomy, precutting EMR, endoscopic submucosal dissection, polypectomy, endoscopic full-thickness resection

Received: May 08, 2020; Accepted: May 26, 2020; Published: May 29, 2020 
or undifferentiated cancers are usually considered as high risk, although poor differentiation in the context of MMR deficiency/MSI is considered as low risk. Abundant evidence suggests that MMR status is a valuable prognostic and predictive biomarker for nonmetastatic colorectal cancer and so should be performed routinely [10].

\section{Endoscopic treatment options}

The successful removal of early colorectal cancer requires advanced techniques and expertise of the endoscopists. Currently different options are available:

\section{Snare polypectomy}

Snare polypectomy may be further classified into hot (HSP) and cold (CSP) snare polypectomy. The basic difference is the use of a high frequency generator for HSP. The disadvantages of conventional hot snare resection are caused by thermal injury. The most common adverse events resulting from this procedure are gastrointestinal bleeding, colonic perforation, and local peritonitis [11]. Recently, the European guidelines considered Cold snare polypectomy the preferred technique for removal of diminutive polyps (size $\leq 5 \mathrm{~mm}$ ). This technique has high rates of complete resection, adequate tissue sampling for histology, and low complication rates. In addition, CSP is suggested for removal of sessile polyps 6-9 $\mathrm{mm}$ in size because of its superior safety profile, although evidence comparing efficacy with HSP is lacking [12].

A recent meta-analysis and systematic review of hot snare vs. cold snare polypectomy for endoscopic removal of 4-10 mm colorectal polyps showed that there is no statistically significant difference between the two techniques, although the rate of overall complications is higher with CSP; however, this is self-limiting [13].

In a recent study, the resection rates and safety profile of cold vs. hot snare polypectomy in polyps sized 5-10 $\mathrm{mm}$ and $11-20 \mathrm{~mm}$ were assessed [14]. Giving further evidence that the cold snare is not inferior to the hot snare for adenomas sized 5-10 $\mathrm{mm}$ and should be preferred, regarding the better safety and cost-effectiveness.

In addition, cold snare resection is an emerging technique for removal of large non pedunculated polyps. Success of this technique has been demonstrated both with [15] and without submucosal injectate [16] and offers the benefit of avoiding thermal injury and reducing or eliminating the risk of late post-polypectomy bleeding.

Recent studies [17-19] suggest that cold snare polypectomy is associated with more superficial resection in comparison with a hot snare or EMR and in the case of small early invasive tumors cold snare resection can potentially lead to positive vertical margins and recurrence. Despite the fact that invasive colorectal lesions less than 10 $\mathrm{mm}$ are rare it is necessary to underline that cold snare is not suitable for suspicious polyps (such as 2B JNET lesions).

In summary, cold snare resection is becoming the standard of treatment for non-suspicious diminutive (up to $5 \mathrm{~mm}$ ) and also to small sessile non-cancerous polyps (up to $9 \mathrm{~mm}$ ). Further studies are needed to evaluate the safety, outcomes, and the exact role of cold snare resection for larger polyp removal.

\section{Endoscopic mucosal resection}

Endoscopic mucosal resection (EMR) was first described by Deyhle et al. in 1973 [20] that is indicated for lesions confined to the mucosa of the colon with a negligible risk of lymph node involvement. Lesions that are $2 \mathrm{~cm}$ or smaller can often be removed "en bloc", whereas larger lesions may require endoscopic piecemeal mucosal resection

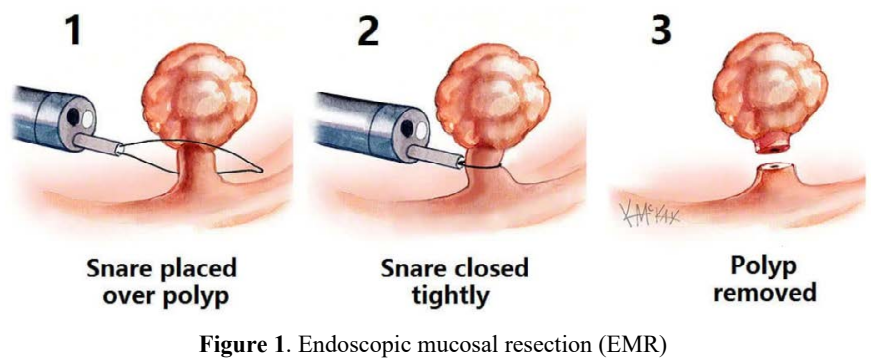

(EPMR). EMR combines the classic principles of conventional snare polypectomy with the addition of submucosal fluid injection as shown in figure 1. In difficult areas such as the ileocecal valve, the anorectal junction, or a proximal location on a fold, a cap attached to the tip of the colonoscope may be helpful to stabilize the position. Normal saline is the most commonly used solution worldwide because of its low cost and ease of use. However, the submucosal cushion is relatively short-lived, and the mucosal elevation tends to be more diffuse. Due to the short life span of saline, endoscopists have developed multiple alternative agents to improve lifting duration, as well as chromoendoscopic agents to improve visualization of the submucosa. Agents commonly used to increase the lifting duration include hydroxypropyl methylcellulose, glycerol, starch volume expanders, hyaluronic acid and Eleview gel. The inability to raise the base of a lesion after submucosal solution injection can indicate the presence of cancer invasion deep into the submucosa. Therefore, EMR should be attempted only if complete resection of neoplastic lesions is expected [21]. The remnants lesion ablation can be performed carefully with electrocautery. Specific alternative techniques include argon plasma coagulation (APC) and low voltage electrocoagulation with the tip of the snare ("snare tip soft coagulation") [22]. APC is associated with a higher rate of tumor recurrence and is not recommended. At the same time snare tip soft coagulation to the normal-appearing margin of EMR defects leads to dramatic reduction in recurrence rates [23]. EMR is complicated by colonic perforation in approximately $1 \%$ to $2 \%$ of cases [24]. In these cases, an endoscopic clip closure should be attempted, but if it is not possible, the patient should be referred to surgery. According to published meta-analysis prophylactic clipping is not associated with a decrease in post polypectomy bleeding rate [25-26].

A large meta-analysis showed that endoscopic resection including ESD and EMR for large polyps appeared to be effective in preventing surgery in $92 \%$ of the cases [27]. Endoscopic resection appeared also to be a safe technique with surgery for adverse event limited to $1 \%$ of the patients. The main reason for endoscopic resection failure was represented by invasive cancer at histology. Endoscopic recurrence occurred in nearly $14 \%$ of the cases, and it was amenable to further endoscopic treatment in most cases. In our opinion, EMR studies would show an increased recurrence but lower complication rates, however, ESD would show lower recurrence but higher complication rates.

A simple method for stratifying lesion complexity, based on the size, morphology, site, and access (SMSA) as depicted in table 1 [28], has been developed by a working group of UK experts [29]. It stratifies polyps into four levels of difficulty.

The main limitation of EMR is the piecemeal nature of resection for polyps $>20 \mathrm{~mm}$ proximal to the splenic flexure, and $>25 \mathrm{~mm}$ in the sigmoid and rectum. Piecemeal resection makes it difficult for the pathologist to comment on completeness of resection. Piecemeal resection is associated with a risk of recurrence around 12\% [30]. A recent cohort demonstrated that thermal ablation of the post-EMR 
Table 1. SMSA (Size, Morphology, Site, and Access) polyp score and level [28]

\begin{tabular}{|l|l|l|l|l|l|l|l|}
\hline $\begin{array}{l}\text { SMSA polyp } \\
\text { score and level }\end{array}$ & & & & & & & \\
\hline $\begin{array}{l}\text { SMSA polyp } \\
\text { score }\end{array}$ & & & & & & & \\
\hline Size & Points & Morphology & Points & Access & Points & Site & Points \\
\hline$<1 \mathrm{~cm}$ & 1 & Pedunculated & 1 & Easy & 1 & Left & 1 \\
\hline $1-1.9 \mathrm{~cm}$ & 3 & Sessile & 2 & Difficult & 3 & Right & 2 \\
\hline $2-2.9 \mathrm{~cm}$ & 5 & Flat & 3 & & & & \\
\hline $3-3.9 \mathrm{~cm}$ & 7 & & & & & & \\
\hline$>4 \mathrm{~cm}$ & 9 & & & & & & \\
\hline SMSA level & Points & & & & & & \\
\hline 1 & $4-5$ & & & & & & \\
\hline 2 & $6-9$ & & & & & & \\
\hline 3 & $9-12$ & & & & & & \\
\hline 4 & $>12$ & & & & & & \\
\hline
\end{tabular}

defect margin with snare tip soft coagulation STSC resulted in a highly significant reduction in adenoma recurrence post piecemeal EMR at first surveillance colonoscopy from $36.4 \%$ in the control arm to $3.3 \%$ in the STSC arm was observed [23]. This simple and safe technique overcomes the major limitation of piecemeal EMR and elevates it to a new level of efficacy, with recurrence rates similar to more complex and resource intensive techniques such as endoscopic submucosal dissection. An additional drawback of EMR "piecemeal" resection is the failure to effectively grade or cure early cancers due to the multipiece nature of resection leading to unnecessary surgery in such cases.

Despite these inherent deficiencies, we believe that colorectal EMR is a very effective technique in expert hands for carefully assessed polyps that do not have any evidence of invasion, and remains the mainstay of treatment for the vast majority of benign colonic polyps. However, it carries a risk of recurrence which can be minimized by wide field resection and soft tip coagulation.

Underwater EMR (U-EMR) is a procedure that follows the strategy to avoid the submucosal injection. The procedure consists of filling the colonic lumen with water in order to achieve a safe cutting line across the submucosal layer, due to the floating effect of the mucosa thus theoretically reducing the risk of deep thermal injury and perforation. In case of large colorectal polyps, underwater EMR (UEMR) was directly compared to conventional EMR with regards to efficacy and safety [31]. UEMR was associated with fewer recurrences and earlier curative resections compared to conventional EMR with no significant difference in adverse events rate. A recent study showed that underwater EMR achieved a higher en bloc resection as compared to the EMR group $68 \%$ vs. $49 \%$ ( $\mathrm{p}>0.05$ ). U-EMR showed a noteworthy trend to achieve an en bloc and complete resection compared to EMR for recurrent lesions ( $33 \%$ vs. $10 \%$; $\mathrm{p}=0.04)$. UEMR was also a more efficient technique than EMR (less time spent per procedure) and there were no additional difficulties encountered by the endoscopist. With regard to the complications rate, post procedural bleeding was the most likely adverse event, mainly related to EMR ( $10 \% v s .2 \%$; p > 0.05) [32]. While we wait for proof of possible superiority to conventional EMR in randomized trials, the technique may be suggested as an alternative to EMR when dealing with large colorectal lesions. A recent prospective study analysed the applications of U-EMR and EMR in the real clinical practice, by comparing the outcomes of both techniques. This comparative study is the first to compare the efficacy and safety of both techniques for polyps larger than $15 \mathrm{~mm}$ in size. In conclusion, U-EMR and EMR have proved to be equivalents in terms of efficacy and safety in the real clinical practice. However, in challenging scenarios such as recurrent lesions or difficult locations, better en bloc resection rates may be achieved with U-EMR. Besides, U-EMR could reduce the likelihood of thermal artifacts in the pathologic specimens, particularly in sessile serrated adenomas [33]. However, and in spite of these encouraging results, we should wait for future randomized control trials to confirm these results.

\section{Endoscopic submucosal dissection}

Endoscopic submucosal dissection (ESD) is an advanced endoscopic technique developed in Japan that allows for curative resection of superficial neoplasms in the gastrointestinal tract [34] (Figures 2 and 3). Its advantage over traditional endoscopic mucosal resection (EMR) is in its ability to achieve 'en bloc' resection of lesions $>2 \mathrm{~cm}$ and avoiding piecemeal resection that is associated with local recurrence. ESD is a challenging procedure from a technical standpoint because of less space in the colon, difficult positioning, a thin bowel walls (especially on the right side), and the presence of colonic folds [35]. The main indication for ESD is an early, invasive lesion confined to the mucosa or superficial submucosa measuring greater than $20 \mathrm{~mm}$ in diameter. Lesions with shallow submucosal invasion and lesions measuring less than $20 \mathrm{~mm}$ but containing significant submucosal fibrosis precluding EMR can also be considered for ESD. The main contraindication of ESD is a deep submucosal invasion; Sm2 [36]. In western countries, ESD has been adopted but in very limited cases as cited above $[37,38]$. ESD is much more technically demanding than EMR and requires longer procedure times, with a median procedure time of $68 \mathrm{~min}$ in a recent meta-analysis [39]. The procedure time and level of complexity depend primarily on endoscopic access to the lesion and access to the submucosal compartment as well as endoscopist skills [40].
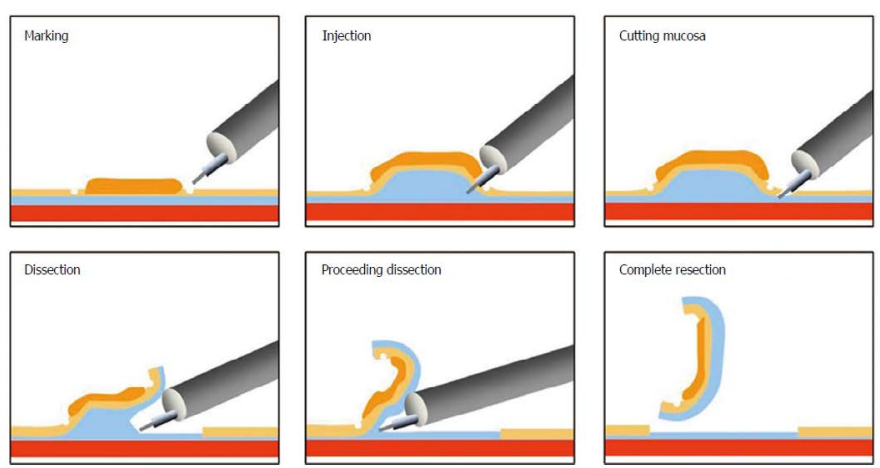

Figure 2. Image of endoscopic submucosal dissection [34]

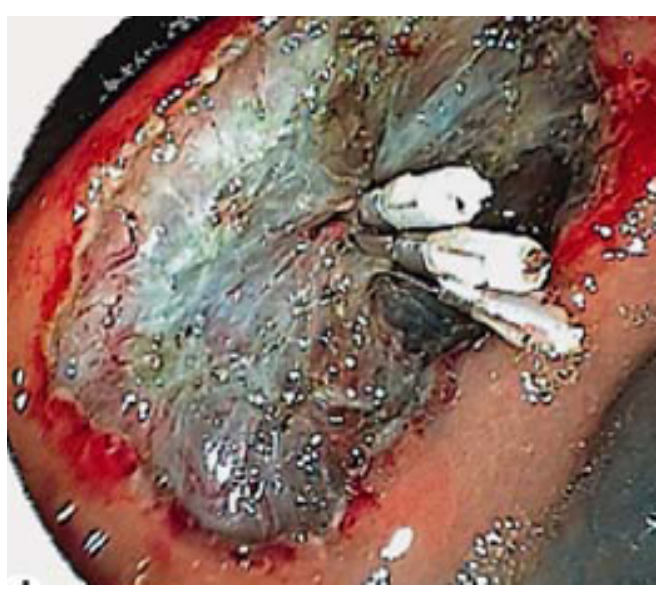

Figure 3. Endoscopic submucosal dissection site of ESD after which clipping was done. 
Current European guidelines consider ESD for removal of colonic and rectal lesions with high suspicion of limited submucosal invasion that is based on two main criteria of depressed morphology and irregular or nongranular surface pattern, particularly if the lesions are larger than $20 \mathrm{~mm}$; [41] or ESD can be considered for colorectal lesions that otherwise cannot be optimally and radically removed by snare-based techniques [41]. A recent meta-analysis by Arezzo et al. [39] evaluated ESD vs. EMR for the treatment of colorectal lesions more than $20 \mathrm{~mm}$ preoperatively assessed as noninvasive. ESD was associated with higher rates of en-bloc resection (89.9 vs. $34.9 \%)$ and histologically complete resection rate $(79.6$ vs. $36.2 \%)$ than EMR, as well as a lower rate of local recurrence ( 0.7 vs. $12.7 \%)$ than EMR. ESD achieves a higher rate of en bloc and histologically complete resection than EMR, with very few recurrences.

Dissemination of ESD in western countries has been slow and only a handful centres in Europe have established comprehensive and proficient ESD programs. Although there has been an increase in the number of published reports on colorectal ESD from western countries the majority of these are relatively small. In a recent study that evaluated implementation of ESD in the treatment of colorectal neoplasia in a Western centre, an 'en bloc' resection rate of $80 \%$ and $\mathrm{R} 0$ resection rate of $69 \%$ [42]. This outcome in efficacy is also in line with previous larger series of colorectal ESD in western countries with an en bloc and R0 resection $[43,44]$. Both en bloc and R0 resection rates are lower than in studies from Asian populations [45-48]. Lee et al. [48] demonstrated that the overall en bloc resection and curative resection rate was $97.5 \%$ and $91.2 \%$ respectively among 1000 ESD procedures. Furthermore, it is important to note that en bloc and $\mathrm{R} 0$ resection rates were significantly higher in the distal colon and rectum compared to the proximal colon, which is in line with previous reports on colorectal ESD [43,45], suggesting that ESD in the right colon is more difficult and associated with longer learning curves compared to ESD in the distal colon and rectum.

Typically, follow-up after ESD is based on the status of the margins; if the margins are negative, recurrence rates are very low, and surveillance can be deferred for at least 1 year. If the margins are positive but there is otherwise no indication for surgical resection, then follow-up can be performed in 3 to 6 months.

In addition, while the concept of en bloc resection of neoplasia is appealing, ESD also has higher costs than EMR. A recent costeffectiveness analysis of wide-field EMR $v s$. ESD concluded that selective ESD for high-risk lesions is the most cost-effective application of colorectal ESD [49]. Compared with laparoscopic surgery, ESD has major advantages, although a formal head-to-head comparison is still lacking [50,51].

Adverse events are more common for ESD than for EMR. The major reported complications of ESD include bleeding and perforation. Most perforations are minor and can be closed with standard clips or overthe-scope clips during or at the end of the procedure, and the rate of emergency surgery is relatively low (around $0.5 \%$ ). Delayed bleeding is observed after $1.5 \%$ of interventions [47]. Therefore, post ESD ulcers should be observed cautiously and if exposed vessels are identified, they can be coagulated via hemostatic forceps or APC. If the vessels are large, clipping is a useful measure to prevent delayed bleeding [52]. Strictures are observed only occasionally, e.g., after circumferential resections in the rectum [53].

We believe that in expert hands higher en bloc resection rates for selected lesions are obtained with ESD, but they come at the cost of higher complication and longer procedure times.
In the western countries standard ESD remains a challenge. Therefore, a simplified technique has been reported to overcome this issue consisting of circumferential mucosal incision around the tumor and subsequently a knife-assisted snare resection is performed [54]. The latter procedure has been previously defined as "precutting EMR" by Japanese experts [2]. A study aimed to compare the effectiveness and outcomes of EMR, EMR-precutting (EMR-P), and ESD in the treatment of 523 colorectal tumors $20 \mathrm{~mm}$ in size or larger. It showed that the en bloc resection rates were 42.9\% (EMR), 65.2\% (EMR-P), and $92.7 \%$ (ESD), and the complete resection rates were $32.9 \%$ (EMR), 59.4\% (EMR-P), and $87.6 \%$ (ESD). The recurrence rates were $25.9 \%$ (EMR; median follow-up period, 26 months), 3.2\% (EMR-P; median follow-up period, 16 months), and $0.8 \%$ (ESD; median follow-up period, 17 months) [55]. This wasn't a randomized trial but suggested technical superiority of pre-cut EMR over conventional EMR but not as good as ESD. Therefore, EMR-P can be used as a transition to ESD. In the largest reported Western series on "hybrid ESD" in the colon, the feasibility, efficacy and safety of this technique was demonstrated in the treatment of large complex polyps (mean size: $46 \mathrm{~mm}$ ), with or without fibrosis and at all sites. Cure rates were $87 \%$ after the first attempt, improving to $95.6 \%$ with further attempts. En bloc resection rate showed a linear increase and reached almost $80 \%$ as the endoscopist's cumulative experience approached 100 cases. The perforation rate (1.2\%) and bleeding rate (4.7\%) were acceptable and managed conservatively in most patients. Therefore, "hybrid ESD" has shown better outcomes than either EMR or ESD in selected cases [56]. A further meta-analysis also examined 8 studies which directly compared standard ESD technique with hybrid ESD technique. The R0 and en bloc resection rates with the hybrid technique were significantly lower than those achieved with the standard technique: $60.6 \%$ and $68.4 \%$, as compared to conventional ESD at $82.9 \%$ and $91 \%$ respectively. However, the adverse event rate was similar in both techniques [55]. It appears that hybrid ESD is an effective step in transition from EMR to ESD but to date, no prospective RCT has been performed comparing outcome of hybrid ESD with EMR or ESD.

\section{Endoscopic full-thickness resection (EFTR)}

The endoscopic treatment of neoplasms in the GI tract witnesses a major breakthrough with the introduction of the EFTR technique. The minimally invasive surgical methods for a full thickness resection of an early rectal cancer include transanal endoscopic microsurgery (TEMS) and transanal minimally invasive surgery (TAMIS), and like the EFTR, they usually lead to full-thickness resection specimens of rectal lesions. Whereas these transanal surgical methods are limited to the rectum, the EFTR using the FTRD ${ }^{\circ}$ can be implemented in all sections of the colorectum, including the cecum.

The FTRD” ("Full Thickness Resection Device”; Ovesco, Tuebingen, Germany) has been approved for EFTR in the lower GI tract in Europe since September 2014. The FTRD consists of an over-the-scope-clip (OTSC) system cap with a 14-mm distally integrated monofilament polypectomy snare (Figure 4). The cap has an inner diameter of $13 \mathrm{~mm}$ and a length of $23 \mathrm{~mm}$ (measured from the tip of the endoscope). The snare handle runs along the outer surface of the colonoscope, under a plastic sheath that is fixed to the instrument. First resection area limits were marked using coagulation with a delivered probe included in the resection device. Then a forceps (FTRD grasper) is used via the operating channel to grasp and pull the lesion inside the cap. Immediately afterwards, the OTSC is released and the lesion is resected en bloc above the clip using the pre-mounted electrosurgical snare included in the device (Figure 5). 


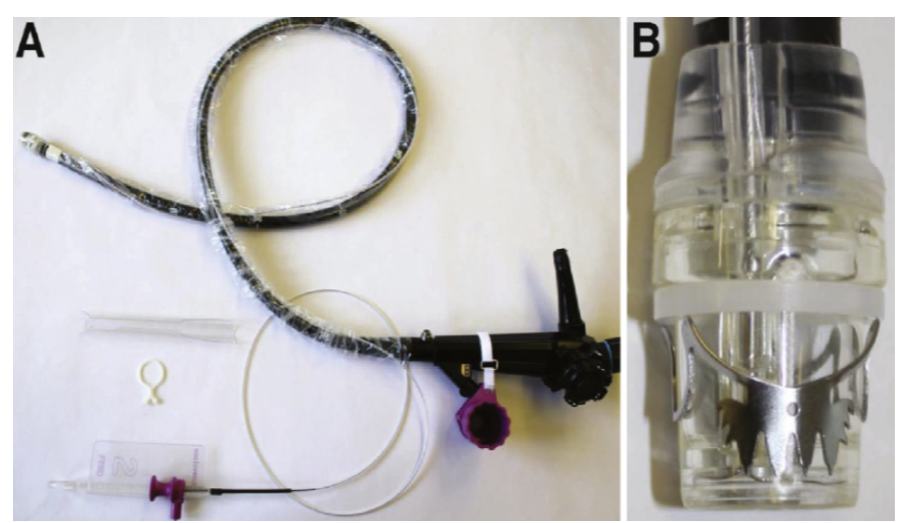

Figure 4. Full Thickness Resection Device:(A) Full thickness resection device system (B) Cap containing the bear claw clip and the grapser

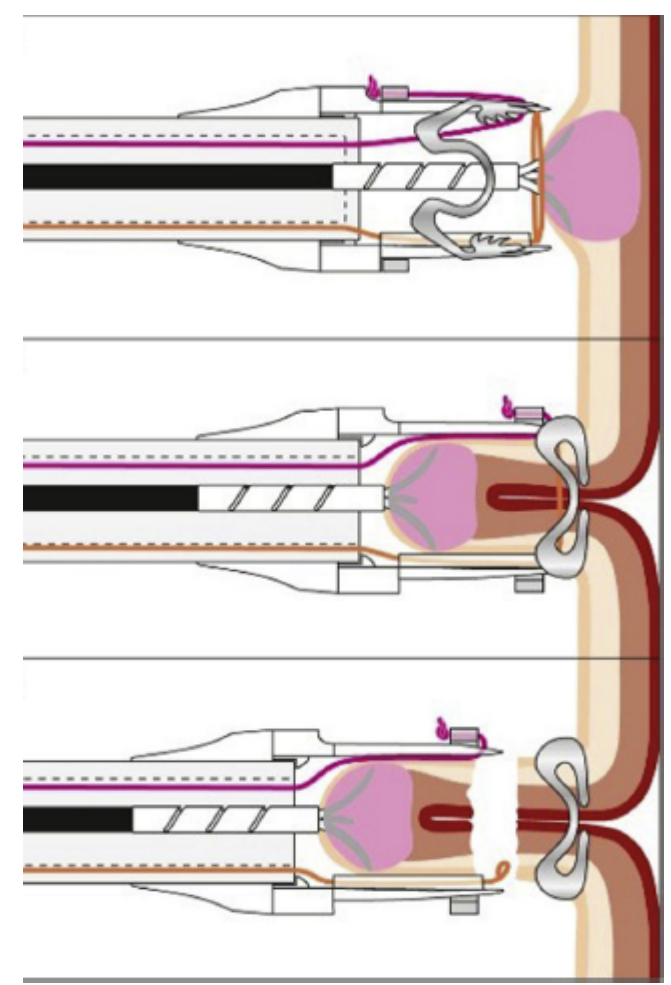

Figure 5. Endoscopic full thickness resection image. The lesion is held with the grasper and pulled into the cap then it is resected with the bear claw clip

EFTR using the FTRD ${ }^{\circ}$ offers an important alternative for the endoscopic treatment of difficult lesions that when treated with EMR or ESD may result in perforation of the colon. Such lesions include polyps with the "nonlifting sign" due to scarring, recurrent lesions, or lesions with submucosal infiltration. Neoplasms arising in the appendicular orifice or in close proximity to diverticula have also been shown to be resectable with EFTR. It may also have a role in the resection of submucosal tumors, such as carcinoids or GISTs, and further research in these areas is needed. A recent multicentric prospective study, doing EFTR using the FTRD ${ }^{\circ}$ reported technical success in $89.5 \%$ with an $\mathrm{R} 0$ resection rate of $76.9 \%$, and in cases with cancer, $\mathrm{R} 0$ resection was achieved in $72.4 \%$ [57]. EFTR is particularly useful for the resection of smaller (up to $15-20 \mathrm{~mm}$ ) nonlifting lesions. To date, there are only limited data on the efficacy of the method, usually performed with the FTRD device [58]. Procedure time depends mainly on the location of the lesion (sometimes passage to proximal locations can be difficult or even impossible). It is more time consuming than EMR, and the size of the lesions is limited by the size of the cap. EFTR was shown to be safe with a $2.2 \%$ rate of emergency surgery due to complications [56].

\section{Conclusion}

The endoscopic treatment of early colorectal cancer should be considered as a viable alternative to surgery and can be considered as the treatment of choice for most colorectal lesions. The techniques are in a state of flex, with a movement away from piecemeal resection towards 'en-bloc' resection. They are relatively easy and quick to perform in terms of technique and have a relatively low complication rate. Snare polypectomy technique has an emerging role for removal of large non pedunculated polyps with an acceptable efficacy and safety profile that should be confirmed in further studies. Underwater EMR may be suggested as an alternative to EMR when dealing with large, recurrent lesions or difficult locations, they achieve better en bloc resection rates. Whilst the data is decisive that in expert hands ESD provides a better outcome when compared to EMR, the biggest challenge in the west will be training endoscopists the techniques, which have a steep learning curve. Techniques like hybrid ESD seems to offer an effective step in transition from EMR to ESD and provides a route to becoming proficient at ESD.

The range of lesions which can be managed endoscopically are growing, and early submucosal invasive tumors can now be considered for ESD or the new full thickness resection devices. These techniques have significantly improved morbidity and mortality associated with cancer resection while at the same time maintaining excellent clinical and oncologic outcomes. A surgical approach is still warranted in certain situations especially where endoscopic treatment fails or in the presence of high-risk features/complicated endoscopies.

As colorectal cancer screening programs have led to an increase the detection of early-stage colorectal cancer, physicians, health-care providers, surgeons, and gastroenterologists must be educated on the possibilities, strengths, and pitfalls of these methods and ensure that their patients are informed and guided adequately.

\section{References}

1. Bretthauer M, Kaminski MF, Loberg M, Zauber AG, et al. (2016) Population-based colonoscopy screening for colorectal cancer: a randomized clinical trial. JAMA Intern Med 176: 894-902. [Crossref]

2. Tanaka S, Kashida H, Saito Y, Yahagi N, Yamano H, et al. (2015) JGES guidelines for colorectal endoscopic submucosal dissection/endoscopic mucosal resection. Dig Endosc 27: 417-434. [Crossref]

3. Cho SJ, Kakar S (2015) Tumor Budding in Colorectal Carcinoma: Translating a Morphologic Score Into Clinically Meaningful Results. Arch Pathol Lab Med 142: 952-957. [Crossref]

4. Beaton C, Twine CP, Williams GL, Radcliffe AG (2013) Systematic review and metaanalysis of histopathological factors influencing the risk of lymph node metastasis in early colorectal cancer. Colorect Dis 15: 788-797. [Crossref]

5. Lugli A, Kirsch R, Ajioka Y, Bosman F, Cathomas G, et al. (2017) Recommendations for reporting tumor budding in colorectal cancer based on the International Tumor Budding Consensus Conference (ITBCC) 2016. Mod Pathol 30: 1299-1311. [Crossref]

6. Nakadoi K, Tanaka S, Kanao H, Terasaki M, Takata S, et al. (2012) Managemen of $\mathrm{T} 1$ colorectal carcinoma with special reference to criteria for curative endoscopic resection. Gastroenterol Hepatol 27: 1057-1062. [Crossref]

7. Oka S, Tanaka S, Nakadoi K, Kanao H, Chayama K (2013) Risk analysis of submucosal invasive rectal carcinomas for lymph node metastasis to expand indication criteria for endoscopic resection. Dig Endosc 25: S21-S25. [Crossref]

8. Yim K, Won DD, Lee IK, Oh ST, Jung ES, et al. (2017) Novel predictors for lymph node metastasis in submucosal invasive colorectal carcinoma. World J Gastroenterol 23: 5936-5944. [Crossref] 
9. Brierley JD, Gospodarowicz MK, Wittekind C (2017) The TNM Classification of Malignant Tumors. ( $8^{\text {th }}$ edn), John Wiley and Sons, Ltd. Chichester, West-Sussex, UK.

10. Kawakami H, Zaanan A, Sinicrope FA (2015) Implications of mismatch repairdeficient status on management of early stage colorectal cancer. $J$ Gastrointest Oncol 6: 67684. [Crossref]

11. Waye JD, Kahn O, Auerbach ME (1996) Complications of colonoscopy and flexible sigmoidoscopy. Gastrointest Endosc Clin N Am 6: 343-377. [Crossref]

12. Ferlitsch M, Moss A, Hassan C, Bhandari P, Dumonceau JM, et al. (2017) Colorectal polypectomy and endoscopic mucosal resection (EMR): European Society of Gastrointestinal Endoscopy (ESGE) Clinical Guideline. Endoscopy 49: 270-297. [Crossref]

13. Jegadeesan R, Aziz M, Desai M, Sundararajan T, Gorrepati VS, Chandrasekar VT, et al. (2019) Hot snare vs. cold snare polypectomy for endoscopic removal of 4-10mm colorectal polyps during colonoscopy: a systematic review and meta-analysis of randomized controlled studies. Endosc Int Open 7: E708-E716. [Crossref]

14. Gessl I, Waldmann E, Penz D, Majcher B, Dokladanska A, et al. (2019) Resection rates and safety profile of cold vs. hot snare polypectomy in polyps sized 5-10 $\mathrm{mm}$ and 1120 mm. Dig Liver Dis 51: 536-541. [Crossref]

15. Piraka C, Saeed A, Waljee AK, Pillai A, Stidham R, et al. (2017) Cold snare polypectomy for non-pedunculated colon polyps greater than $1 \mathrm{~cm}$. Endoscopy Int Open 5: E184-E189. [Crossref]

16. Tate DJ, Awadie H, Bahin FF, Desomer L, Lee R, et al. (2018) Wide-field piecemeal cold snare polypectomy of large sessile serrated polyps without a submucosal injection is safe. Endoscopy 50: 248-252. [Crossref]

17. Suzuki S, Gotoda T, Kusano C, Ikehara H, Sugita A, et al. (2018) Width and depth of resection for small colorectal polyps: hot versus cold snare polypectomy. Gastrointest Endosc 87: 1095-1103. [Crossref]

18. Ito A, Suga T, Ota H, Tateiwa N, Matsumoto A, et al. (2018) Resection depth and layer of cold snare polypectomy versus endoscopic mucosal resection. $J$ Gastroenterol 53 : 1171-1178. [Crossref]

19. Kato M, Shiraishi J, Uraoka T (2017) Second local recurrence with advanced rectal cancer after salvage endoscopic mucosal resection of local recurrence following initial cold polypectomy. Dig Endosc 29: 636. [Crossref]

20. Deyhle P, Largiader F, Jenny S (1973) A method for endoscopic electroresection of sessile colonic polyps. Endoscopy 5: 38-40.

21. Kobayashi N, Saito Y, Sano Y, Uragami N, Michita T, et al. (2007) Determining the treatment strategy for colorectal neoplastic lesions: endoscopic assessment or the nonlifting sign for diagnosing invasion depth? Endoscopy 39: 701-705. [Crossref]

22. Liaquat H, Rohn E, Rex DK (2013) Prophylactic clip closure reduced the risk of delayed postpolypectomy hemorrhage: experience in 277 clipped large sessile or flat colorectal lesions and 247 control lesions. Gastrointest Endosc 77: 401-407. [Crossref]

23. Klein A, Tate DJ, Jayasekeran V, Hourigan L, Singh R, et al. (2019) Thermal Ablation of Mucosal Defect Margins Reduces Adenoma Recurrence After Colonic Endoscopic Mucosal Resection. Gastroenterol 156: 604-613. [Crossref]

24. Moss A, Bourke MJ, Williams SJ, Hourigan LF, Brown G, et al. (2011) Endoscopic mucosal resection outcomes and prediction of submucosal cancer from advanced colonic mucosal neoplasia. Gastroenterol 140: 1909-1918. [Crossref]

25. Forbes N, Frehlich L, James MT, Hilsden RJ, Kaplan GG, et al. (2019) Routine Prophylactic Endoscopic Clipping Is Not Efficacious in the Prevention of Delayed Post-Polypectomy Bleeding: A Systematic Review and Meta-Analysis of Randomized Controlled Trials. J Can Assoc Gastroenterol 2: 105-117. [Crossref]

26. Nishizawa T, Suzuki H, Goto O, Ogata H, Kanai T, et al. (2017) Effect of prophylactic clipping in colorectal endoscopic resection: A meta-analysis of randomized controlled studies. United European Gastroenterol J 5 859-867. [Crossref]

27. Hassan C, Repici A, Sharma P, Correale L, Zullo A, et al. (2016) Efficacy and safety of endoscopic resection of large colorectal polyps: a systematic review and metaanalysis. Gut 65: 806-820. [Crossref]

28. Longcroft-Wheaton G, Duku M, Mead R, Basford P, Bhandari P (2013) Risk stratification system for evaluation of complex polyps can predict outcomes of endoscopic mucosal resection. Dis Colon Rectum 56: 960-966. [Crossref]

29. Gupta S, Miskovic D, Bhandari PS, Dolwani S, McKaig B, et al. (2013) A novel method for determining the difficulty of colonoscopic polypectomy. Frontline Gastroenterol 4: 244-248. [Crossref]
30. De Ceglie A, Hassan C, Mangiavillano B, Matsuda T, Saito Y, et al. (2016) Endoscopic mucosal resection and endoscopic submucosal dissection for colorectal lesions: a systematic review. Crit Rev Oncol Hematol 104: 138-155. [Crossref]

31. Schenck RJ, Jahann DA, Patrie JT, Stelow EB, Cox DG, al. (2017) Underwater endoscopic mucosal resection is associated with fewer recurrences and earlier curative resections compared to conventional endoscopic mucosal resection for large colorectal polyps. Surg Endosc 31: 4174-4183. [Crossref]

32. Spadaccini M, Fuccio L, Lamonaca L, Frazzoni L, Maselli R, et al. (2019) Underwater EMR for colorectal lesions: a systematic review with meta-analysis (with video). Gastrointest Endosc 89: 1109-1116.e4.

33. Rodríguez Sánchez J, Uchima Koecklin H, González López L, Cuatrecasas M, de la Santa Belda E, et al. (2019) Short and long-term outcomes of underwater EMR compared to the traditional procedure in the real clinical practice. Rev Esp Enferm Dig 111: 543-549. [Crossref]

34. Fuccio L, Hassan C, Ponchon T, Mandolesi D, Farioli A, et al. (2017) Clinical outcomes after endoscopic submucosal dissection for colorectal neoplasia: a systematic review and meta-analysis. Gastrointest Endosc 86: 74-86. [Crossref]

35. Kantsevoy SV, Adler DG, Conway JD (2008) ASGE Technology Committee Endoscopic mucosal resection and endoscopic submucosal dissection. Gastrointest Endosc 68: 11-18.

36. Othman MO, Wallace MB (2011) Endoscopic mucosal resection (EMR) and endoscopic submucosal dissection (ESD) in 2011, a Western perspective. Clin Res Hepatol Gastroenterol 35: 288-294. [Crossref]

37. Draganov PV, Gotoda T, Chavalitdhamrong D, Wallace MB (2013) Techniques of endoscopic submucosal dissection: application for the Western endoscopist? Gastrointest Endosc 78: 677-688. [Crossref]

38. Farhat S, Chaussade S, Ponchon T, Coumaros D, Charachon A, et al. (2011) Endoscopic submucosal dissection in a European setting. A multi-institutional report of a technique in development. Endoscopy 43: 664-670. [Crossref]

39. Arezzo A, Passera R, Marchese N, Galloro G, Manta R, et al. (2016) Systematic review and metaanalysis of endoscopic submucosal dissection vs endoscopic mucosal resection for colorectal lesions. United European Gastroenterol J 4: 18-29. [Crossref]

40. Takeuchi Y, Iishi H, Tanaka S, Saito Y, Ikematsu H, et al. (2014) Factors associated with technical difficulties and adverse events of colorectal endoscopic submucosal dissection: retrospective exploratory factor analysis of a multicenter prospective cohort. Int J Colorectal Dis 29: 1275-1284. [Crossref]

41. Pimentel-Nunes P, Dinis-Ribeiro M, Ponchon T, Repici A, Vieth M, et al. (2015) Endoscopic submucosal dissection:European Society of Gastrointestinal Endoscopy (ESGE) guideline. Endoscopy 47: 829-854. [Crossref]

42. Rönnow CF, Uedo N, Toth E, Thorlacius H (2018) Endoscopic submucosal dissection of 301 large colorectal neoplasias: outcome and learning curve from a specialized center in Europe. Endosc Int Open 6: E1340-E1348.

43. Sauer M, Hildenbrand R, Oyama T, Sido B, Yahagi N, et al. (2016) Endoscopic submucosal dissection for flat or sessile colorectal neoplasia $>20 \mathrm{~mm}$ : A European single-center series of 182 cases. Endosc Int Open 4: E895-E900. [Crossref]

44. Spychalski M, Skulimowski A, Dziki A, Saito Y (2017) Colorectal endoscopic submucosa dissection (ESD) in the West - when can satisfactory results be obtained? A single-operator learning curve analysis. Scand J Gastroenterol 52: 1442-1452. [Crossref]

45. Shiga H, Ohba R, Matsuhashi T, Jin M, Kuroha M, et al. (2017) Feasibility of colorecta endoscopic submucosal dissection (ESD) carried out by endoscopists with no or little experience in gastric ESD. Dig Endos 2: 58-65. [Crossref]

46. Repici A, Hassan C, De Paula Pessoa D, Pagano N, Arezzo A, et al. (2012) Efficacy and safety of endoscopic submucosal dissection for colorectal neoplasia: a systematic review. Endoscopy 44: 137-150. [Crossref]

47. Saito Y, Uraoka T, Yamaguchi Y, Hotta K, Sakamoto N, et al. (2010) A prospective, multicenter study of 1111 colorectal endoscopic submucosal dissections (with video). Gastrointest Endosc 72: 1217-1225. [Crossref]

48. Lee EJ, Lee JB, Lee SH, Kim DS, Lee DH, et al. (2013) Endoscopic submucosal dissection for colorectal tumors-1,000 colorectal ESD cases: one specialized institute's experiences. Surg Endosc 27: 31-39. [Crossref]

49. Bahin FF, Heitman SJ, Rasouli KN, Mahajan H, McLeod D, et al. (2018) Wide-field endoscopic mucosal resection versus endoscopic submucosal dissection for laterally spreading colorectal lesions: a cost-effectiveness analysis. Gut 67: 1965-1973. [Crossref]

50. Nakamura F, Saito Y, Sakamoto T, Otake Y, Nakajima T, et al. (2015) Potential perioperative advantage of colorectal endoscopic submucosal dissection versus laparoscopy-assisted colectomy. Surg Endosc 29: 596-606. [Crossref] 
51. Jayanna M, Burgess NG, Singh R, Hourigan LF, Brown GJ, et al. (2016) Cost Analysis of Endoscopic Mucosal Resection vs Surgery for Large Laterally Spreading Colorectal Lesions. Clin Gastroenterol Hepatol 14: 271-278.e1-2 [Crossref]

52. Toyonaga T, Nishino E, Man-I M, East JE, Azuma T (2012) Principles of quality controlled endoscopic submucosal dissection with appropriate dissection level and high quality resected specimen. Clin Endosc 45: 362-374. [Crossref]

53. ASGE Technology Committee, Maple JT, Abu Dayyeh BK, Chauhan SS, Hwang JH, et al. (2015) Endoscopic submucosal dissection. Gastrointest Endosc 81: 1311-1325.

54. Bhattacharyya R, Chedgy FJ, Kandiah K, Longcroft-Wheaton G, Bhandari P (2016) Knife-assisted snare resection (HYBRID ESD) of large and refractory colonic polyps at a Western centre: feasibility, safety and efficacy study to guide future practice. United European Gastroenterol J 4: 466-473. [Crossref]
55. Lee EJ, Lee JB, Lee SH, Youk EG (2012) Endoscopic treatment of large colorectal tumors: comparison of endoscopic mucosal resection, endoscopic mucosal resection-precutting, and endoscopic submucosal dissection. Surg Endosc 26: 2220-2230. [Crossref]

56. Schmidt A, Beyna T, Schumacher B, Meining A, Richter-Schrag HJ, et al. (2018) Colonoscopic full-thickness resection using an over-the-scope device: a prospective multicentre study in various indications. Gut 67: 1280-1289. [Crossref]

57. Al-Bawardy B, Rajan E, Wong Kee Song LM (2017) Over-the-scope clip-assisted endoscopic fullthickness resection of epithelial and subepithelial GI lesions. Gastrointest Endosc 85: 1087-1092 [Crossref]

58. Asano M (2012) Endoscopic submucosal dissection and surgical treatment for gastrointestinal cancer. World J Gastrointest Endosc 4: 438-447. [Crossref]

Copyright: $\mathbb{C} 2020$ Farhat S. This is an open-access article distributed under the terms of the Creative Commons Attribution License, which permits unrestricted use, distribution, and reproduction in any medium, provided the original author and source are credited. 